\title{
PENGARUH SUPERVISI AKADEMIK DAN KEPEMIMPINAN KEPALA SEKOLAH TERHADAP DISIPLIN KERJA GURU
}

\author{
Samsuadi \\ Pengawas Sekolah \\ Jurusan PEP Kekhususan Kepengawasan PPs Universitas Negeri Makassar \\ Email : adysamsuadi@yahoo.co.id
}

\begin{abstract}
The Influence of Academic Supervision Of Supervisors and the Leadership of nthe Principal toward Work Discipline of the Teachers at SMKN 1 Bantaeng. The objectives of the research are to examine (1) the influence of academic supervision of supervisors and the leadership of the principal collaboratively toward work discipline of the teachers at SMKN 1 Bantaeng, (2) the influence of academic supervision of supervisors toward work discipline of the teachers at SMKN 1 Bantaeng, (3) the influence of the leadership of the principal toward work discipline of the teachers at SMKN 1 Bantaeng. The population of the research was the teachers of SMKN 1 Bantaeng with the total of 80 teachers. Samples were selected by using Slovin's formula of the proportionate stratified random sampling and obtained 67 teachers. The instrument used in collecting the data was questionnaire which referred to Likert's scale modified by Hadi. The result of descriptive analysis reveals that academic supervision of supervisors of the principal are in good category. The The result of descriptive analysis reveals that the leadership of the principal and work discipline of the teachers are in very good category. The result of hypothesis test indicates that academic supervision of supervisors and the leadership of the principal collaboratively give influence toward work discipline of the teachers at SMKN 1 Bantaeng. Partially, academic supervision of supervisors gives no influence toward work discipline of the teachers at SMKN 1 Bantaeng; whereas, the leadership of the principal gives influence toward work discipline of the teachers at SMKN 1 Bantaeng.
\end{abstract}

Keywords: Academic supervision, leadership, Work discipline.

\begin{abstract}
ABSTRAK
Tujuan penelitian adalah (1) untuk mengetahui pengaruh supervisi akademik pengawas dan kepemimpinan kepala sekolah secara bersama-sama berpengaruh terhadap disiplin kerja guru SMK Negeri 1 Bantaeng, (2) untuk mengetahui pengaruh supervisi akademik pengawas terhadap disiplin kerja guru SMK Negeri 1 Bantaeng, (3) untuk mengetahui pengaruh kepemimpinan kepala sekolah terhadap disiplin kerja guru SMK Negeri 1 Bantaeng. Populasi penelitian ini adalah guru SMK Negeri 1 Bantaeng yang berjumlah 80 orang, melalui rumus Slovin diperoleh sampel sebanyak 67 orang. Teknik penarikan sampel dilakukan dengan menggunakan teknik proportionate stratified random sampling. Instrumen pengumpulan data yang digunakan adalah angket dengan memakai skala Likert modifikasi Hadi. Hasil analisis deskriptif menunjukkan bahwa supervisi akademik pengawas dan kepemimpinan kepala sekolah berada pada katregori tinggi. Sedangkan dari hasil uji prasyarat tidak ditemukan gejala multikolinieritas, sehingga memenuhi syarat untuk melakukan analisis regresi ganda. Dari hasil uji hipotesis ditemukan bahwa supervisi akademik pengawas dan kepemimpinan kepala sekolah secara bersama-sama berpengaruh terhadap disiplin kerja guru SMK Negeri 1 Bantaeng. Secara parsial supervisi akademik pengawas tidak berpengaruh terhadap disiplin kerja guru SMK Negeri 1 Bantaeng, sedangkan kepemimpinan kepala sekolah berpengaruh terhadap disiplin kerja guru SMK Negeri 1 Bantaeng.
\end{abstract}

Kata kunci : Supervisi akademik, Kepemimpinan, Disiplin guru. 


\section{PENDAHULUAN}

Pendidikan bertujuan untuk meningkatkan kualitas sumber daya manusia. Dalam usaha meningkatkan kualitas sumber daya pendidikan, guru merupakan komponen sumber daya manusia yang harus dibina dan dikembangkan terus-menerus. Potensi sumber daya guru itu perlu terus tumbuh dan berkembang agar dapat melakukan fungsinya secara maksimal. Selain itu pengaruh perubahan yang serba cepat menuntut setiap guru untuk terus-menerus belajar menyesuaikan diri dengan perkembangan ilmu pengetahuan dan teknologi serta mobilitas masyarakat. Peran guru dalam usaha peningkatan mutu pendidikan sangatlah penting. Untuk itu guru dituntut menyelenggarakan proses pembelajaran yang berkualitas. Usaha peningkatan kualitas pembelajaran harus dilakukan secara berkesinambungan, sebab kualitas pembelajaran bersifat dinamis. Berkaitan dengan hal tersebut Quisumbing (dalam Mardapi 2012:3) menyatakan bahwa kualitas pendidikan adalah proses yang bersifat dinamis, tidak statis, dan bukan berupa produk akhir. Sekalipun guru telah memiliki sejumlah kompetensi, tetap saja di lapangan guru akan menemui persoalan dan situasi yang terus berubah, seperti kurikulum, tuntutan masyarakat dan sebagainya

Disiplin tidak hanya menjadi cermin dari sikap positif seorang guru, namun juga akan sangat membantu keberhasilan dalam pelaksanaan tugasnya. Dikatakan oleh Ratminto dan Winarsih, (2005: 47) bahwa sikap disiplin akan sangat membantu seseorang menyelesaikan pekerjaan tepat pada waktunya dan sesuai dengan kondisi yang dipersyaratkan. Disiplinan bukan hanya sekedar sebagai indikasi adanya semangat dan kegairahan kerja, tetapi dapat mempengaruhi efektivitas dan efisiensi pencapaian tujuan dari suatu perusahaan/organisasi. Dengan adanya kedisiplinan, diharapkan pekerjaan akan dilakukan seefektif dan seefisien mungkin. Sebaliknya bila kedisiplinan tidak dapat ditegakkan dengan baik, maka dimungkinkan tujuan-tujuan organisasi yang telah ditetapkan tidak dapat tercapai atau dapat tercapai tetapi secara kurang efektif dan efisien.
Dalam upaya meningkatkan disiplin guru maka peranan pengawas diharapkan dapat memberikan kontribusi yang positif. Dalam hal ini, pengawas yang melaksanakan supervisi akademik secara intensif dapat dilakukan dengan memberikan pembinaan kepada guru, termasuk pembinaan terhadap kedisiplinan guru. Supervisi yang dilakukan oleh pengawas diharapkan dapat meningkatkan disiplin kerja guru. Faktor lain yang juga dapat memberikan pengaruh terhadap kedisiplinan guru adalah kepemimpinan kepala sekolah. Secara teoritis, hal tersebut dapat dikaitkan dengan pentingnya fungsi kepemimpinan dalam suatu organisasi. Pada konteks ini, suatu organisasi tanpa adanya kepemimpinan, organisasi hanya merupakan kelompok manusia yang kacau, tidak teratur, dan tidak akan dapat melahirkan perilaku bertujuan. Kepemimpinan adalah faktor manusiawi yang mengikat suatu kelompok bersama dan memberi motivasi menuju tujuan-tujuan tertentu baik dalam jangka pendek maupun jangka panjang.

Untuk menjaga bahkan meningkatkan mutu pendidikan di sekolah, maka pengawas, kepala sekolah maupun guru dituntut keprofesionalannya untuk melaksakan tugas pokok dan fungsinya sesuai tuntutan kompetensi pengawas, kepala sekolah maupun guru yang tertuang dalam standar nasional pendidikan dan Peraturan Menteri Pendidikan Nasional RI Nomor 12 Tahun 2007 Tentang Standar Pengawas Sekolah/Madrasah. Guru sebagai penjamin mutu pendidikan di dalam kelas sebagai pelaksana kegiatan belajar mengajar, sementara pengawas dan kepala sekolah adalah penjamin mutu pendidikan dalam wilayah yang lebih luas lagi. Adapun yang dimaksud dengan supervisi akademik, menurut Sagala (2010:88) mengatakan bahwa, supervisi diartikan sebagai usaha untuk memperbaiki situasi belajar mengajar, yaitu supervisi sebagai bantuan bagi guru dalam meningkatkan kualitas mengajar untuk membantu peserta didik agar lebih baik dalam belajar. Selanjutnya yang dimaksud dengan kepemimpinan adalah suatu aktivitas mempengaruhi orang-orang untuk berusaha mencapai tujuan kelompok secara sukarela. Kepemimpinan sebagai suatu proses mempengaruhi aktivitas seseorang atau sekelompok orang untuk mencapai tujuan dalam 
situasi tertentu, menurut Terry (dalam Kartono, 2011:57). Adapun menurut Masaong, (2012 : 7) menyatakan fungsi supervisi akademik adalah untuk memperbaki situasi pembelajaran melalui bimbingan guru.

Guru merupakan sebuah profesi sehingga menuntut setiap orang yang menjadi guru untuk mampu mewujudkan profesionalisme dalam pelaksanaan tugas-tugasnya. Salah satu wujud dari profesionalisme tersebut adalah adanya sikap disiplin yang tinggi. Sikap ini berkaitan dengan kepatuhan atau ketaatan terhadap peraturan dan ketentuan yang berlaku. Oleh karena itu guru dalam melaksanakan tugas dituntut untuk melaksanakan tugas dengan penuh tanggung jawab dan disiplin kerja yang tinggi.

Adapun rumusan masalah dalam penelitian ini adalah: (1) Apakah supervisi akademik pengawas dan kepemimpinan kepala sekolah secara bersama-sama berpengaruh terhadap disiplin kerja guru SMK Negeri 1 Bantaeng (2) Apakah supervisi akademik berpengaruh terhadap disiplin kerja guru SMK Negeri 1 Bantaeng dengan mengontrol kepemimpinan kepala sekolah (3) Apakah kepemimpinan kepala sekolah berpengaruh terhadap terhadap disiplin kerja guru SMK Negeri 1 Bantaeng dengan mengontrol supervisi akademik pengawas. Sedangkan tujuan penelitian ini adalah (1) Untuk mengetahui pengaruh supervisi akademik pengawas dan kepemimpinan kepala sekolah terhadap disiplin kerja guru SMK Negeri 1 Bantaeng. (2) Untuk mengetahui pengaruh supervisi akademik pengawas terhadap disiplin kerja guru SMK Negeri 1 Bantaeng (3) Untuk mengetahui pengaruh kepemimpinan kepala sekolah terhadap disiplin kerja guru SMK Negeri 1 Bantaeng.

Adapun hipotesis penelitian ini adalah (1) Supervisi akademik dan kepemimpinan kepala sekolah secara bersama-sama berpengaruh terhadap disiplin kerja guru SMK Negeri 1 Bantaeng. (2) Supervisi akademik berpengaruh terhadap disiplin kerja guru SMK Negeri 1 Bantaeng dengan mengontrol kepemimpinan kepala sekolah(3) Kepemimpinan kepala sekolah berpengaruh terhadap disiplin kerja guru SMK Negeri 1 Bantaeng dengan mengontrol supervisi akademik pengawas.

\section{METODE}

Penelitian ini merupakan penelitian $e x$ post facto dengan menggunakan analisis regresi ganda dengan korelasi parsial. Data yang dikumpulkan dalam penelitian ini berupa data kuantitatif. Pada penelitian ini menggunakan tiga variabel yaitu dua variabel bebas (X) dan satu variabel terikat $(\mathrm{Y})$. Dua variabel bebas tersebut yaitu supervisi akademik pengawas (X1) dan kepemimpinan kepala sekolah (X2), sedangkan variabel terikatnya adalah disiplin kerja guru $(\mathrm{Y})$. Hubungan kausal yang akan dijelaskan dalam penelitian ini adalah pengaruh supervisi akademik pengawas dan kepemimpinan kepala sekolah terhadap disiplin kerja guru SMK Negeri 1 Bantaeng.

Pada penelitian ini jenis instrumen yang digunakan adalah instrumen non tes, berupa kuesioner yang isinya pertanyaan/pernyataan, yang ditanggapi oleh responden yaitu guru SMK Negeri 1 Bantaeng, dengan menggunakan skala Likert modifikasi Hadi (Hadi; 1991:20). Dalam hal ini ada empat kategori yaitu: Sangat Setuju (SS) yang diberi skor 4, Setuju (S) yang diberi skor 3, Tidak Setuju (TS) yang diberi skor 2, Sangat Tidak Setuju (STS) yang diberi skor 1, untuk pertanyaan/pernyataan yang sifatnya positif. Sebaliknya untuk pertanyaan/pernyataan yang sifatnya negatif maka Sangat Setuju (SS) yang diberi skor 1, Setuju (S) yang diberi skor 2, Tidak Setuju (TS) yang diberi skor 3, Sangat Tidak Setuju (STS) yang diberi skor 4. Sementara untuk perilaku, opsi jawabannya meliputi SL $=$ Selalu diberi skor $4, \mathrm{SR}=$ Sering diberi skor 3, JR = Jarang diberi skor 2, dan TP = Tidak Pernah diberi skor 1, untuk pertanyaan/pernyataan yang sifatnya positif. Sebaliknya untuk pertanyaan/pernyataan yang sifatnya negatif maka opsi jawabannya meliputi $\mathrm{SL}=$ Selalu diberi skor $1, \mathrm{SR}=$ Sering diberi skor 2, JR = Jarang diberi skor 3, dan TP = Tidak Pernah diberi skor 4. Pemberian skor tersebut untuk kepentingan pengolahan dengan statistik. Populasi pada penelitian ini adalah semua guru yang mengajar di Sekolah Menengah Kejuruan (SMK) Negeri 1 Bantaeng, dengan jumlah sebanyak 80 orang. Untuk melakukan estimasi 
parameter, penarikan sampel diambil dengan tingkat presisi sebesar $95 \%$ atau tingkat kesalahan $5 \%$. Adapun jumlah sampel yang dapat ditarik dari populasi ditentukan dengan menggunakan rumus Slovin (Noor, 2013:158) berikut:

$$
\mathrm{n}=\frac{N}{1+\left(N X e^{2}\right)}
$$

Keterangan : $\mathrm{n}=$ Jumlah elemen/anggota sampel

$\mathrm{N}=$ Jumlah elemen/anggota populasi

$\mathrm{e}=$ Tingkat kesalahan yang ditetapkan

Jumlah populasi guru SMK Negeri 1 Bantaeng sebanyak 80 orang guru. Jumlah ini kemudian dikelompokkan berdasarkan mata pelajaran, sebagaimana terlihat pada Tabel 1 berikut.

Tabel 1 Distribusi Populasi

\begin{tabular}{lcc}
\hline No. & Mata & $\mathrm{N}_{\mathrm{i}}$ \\
& Pelajaran & 21 \\
1. & Normatif & 23 \\
2. & Adaptif & 36 \\
3. & Produktif & \multicolumn{2}{c}{} \\
\hline
\end{tabular}

Dari Tabel 1 di atas nampak jumlah sampel dari masing-masing kelompok mata pelajaran, yaitu; kelompok mata pelajaran normatif sebanyak 21 orang, kelompok mata pelajaran adaptif sebanyak 23 orang, sedangkan kelompok mata pelajaran produktif sebanyak 36 orang.

Penerapan rumus Slovin menghasilkan sampel minimal sebesar 66,67 kemudian sampel minimal dibulatkan menjadi 67. Untuk menentukan besarnya sampel dari sub-sub populasi seperti yang ada pada Tabel 1 di atas maka dilakukan dengan menerapkan penarikan sampel secara proporsional Random sampel dengan rumus sebagai berikut:

$$
\boldsymbol{n}_{i}=\frac{N_{i}}{N} \boldsymbol{n}
$$

Keterangan: kelompok

$\mathrm{n}_{\mathrm{i}}=$ Jumlah sampel menurut kelompok

$\mathrm{N}_{\mathrm{i}}=$ Jumlah populasi menurut ditetapkan.

$\mathrm{N}=$ Jumlah populasi seluruhnya

$\mathrm{n}$ = Jumlah sampel minimal yang

Berdasarkan rumus tersebut diperoleh sampel untuk masing-masing kelompok atau sub-sub populasi seperti tampak pada tabel 2 berikut ini:

Tabel 2 Penyebaran populasi dan sampel penelitian

\begin{tabular}{llccl}
\hline No. & Mata Pelajaran & $\mathrm{N}_{\mathrm{i}}$ & Proporsi & $\mathrm{n}_{\mathrm{i}}$ \\
\hline 1. & Normatif & 21 & 0,26 & 18 \\
2. & Adaptif & 23 & 0,29 & 19 \\
3. & Produktif & 36 & 0,45 & 30 \\
\hline & Jumlah & 80 & 100 & 67 \\
\hline
\end{tabular}

Dari hasil penyebaran populasi dan sampel pada Tabel 2 di atas, maka penyebaran sampel untuk masing-masing mata pelajaran adalah untuk normatif jumlah sampelnya 
sebanyak 18 orang dari 21 populasi atau $26 \%$, untuk adaptif jumlah sampelnya sebanyak 19 orang dari 23 populasi atau $29 \%$, sedangkan untuk produktif jumlah sampelnya sebanyak 30 orang dari 36 populasi atau $45 \%$.

Penjaringan data dilakukan dengan menggunakan instrument nontes dalam bentuk kuesioner pertanyaan tertutup. Peneliti mengumpulkan data pada guru-guru yang ada di Sekolah Menengah Kejuruan (SMK) Negeri 1 Bantaeng. Kuesioner diberikan kepada guru dengan mendampingi pada saat pengisiannya agar didapatkan data yang akurat dan ekpetasi pengembalian yang relatif tinggi.

Supervisi akademik pengawas adalah usaha dari pengawas dalam upaya memperbaiki pengajaran, termasuk menstimulasi, menyeleksi pertumbuhan jabatan dan perkembangan guruguru serta merevisi tujuan-tujuan pembelajaran, bahan pengajaran dan metode serta evaluasi dan penilaian pengajaran.

Kemudian yang dimaksud kepemimpinan kepala sekolah adalah kemampuan yang menentukan terciptanya kualitas proses belajar mengajar untuk mempengaruhi para guru dan personil sekolah yang lain dalam rangka mencapai tujuan-tujuan sekolah.

Selanjutnya disiplin kerja guru adalah ketaatan atau kepatuhan terhadap norma, peraturan dan ketentuan yang berlaku dalam pelaksanaan kerja di suatu organisasi, termasuk di dalamnya organisasi pendidikan.

Supervisi akademik pengawas adalah skor persepsi guru tentang bantuan profesional pengawas kepada guru dalam upaya memperbaiki pengajaran, termasuk menstimulasi, menyeleksi pertumbuhan jabatan dan perkembangan guru-guru serta merevisi tujuan-tujuan pembelajaran, bahan pengajaran dan metode serta evaluasi dan penilaian pengajaran, yang ditandai dengan indikator: (1) memahami konsep, (2) membimbing guru dalam menyusun silabus, (3) membimbing guru dalam memilih dan menggunakan strategi/metode/teknik pembelajaran, (4) memantau guru dalam kegiatan pembelajaran, (5) membimbing guru dalam mengelola, merawat, mengembangkan, menggunakan media pendi- dikan dan fasilitas pembelajaran, (6) memotivasi guru

Kemudian yang dimaksud kepemimpinan kepala sekolah adalah skor persepsi guru tentang kemampuan kepala sekolah dalam mewujudkan terciptanya kualitas proses belajar mengajar untuk mempengaruhi para guru dan personil sekolah yang lain dalam rangka mencapai tujuan-tujuan sekolah, yang ditandai dengan indikator: (1) educator, (2) manajer, (3) administrator, (4) supervisor, (5) leader, (6) inovator, (7) motivator, dan (8) entrepreneur.

Disiplin kerja guru adalah skor berbagai sikap ketaatan atau kepatuhan terhadap norma, peraturan dan ketentuan yang berlaku dalam pelaksanaan kerja di suatu organisasi, termasuk di dalamnya organisasi pendidikan, yang ditandai dengan dimensi/indikator: (1) frekuensi kehadiran, (2) tingkat kewaspadaan, (3) ketaatan pada standar kerja, (4) ketaatan pada peraturan kerja, (5) etika kerja.

Data yang diperoleh dianalisis dengan menggunakan analisis deskriptif. Analisis deskriptif dilakukan untuk mendeskripsikan dan mengkomunikasikan data mentah dengan singkat, jelas dan rinci dalam bentuk tabel persentase. Disamping itu dalam setiap tabel presentase yang disajikan diikuti dengan komentar atau pendapat ilmiah (expert's judgement) dari peneliti.

Dari pengolahan data mentah tersebut dapat diketahui persentase masing-masing variabel, kemudian dilanjutkan dengan pengkategorian. Kriteria untuk menentukan kategori terhadap tanggapan responden dengan melihat kontribusi butir yang dominan pada variabel yang menyebabkan tinggi rendahnya pengaruh supervisi akademik dan kepemimpinan kepala sekolah terhadap disiplin kerja guru. Untuk melakukan analisis deskriptif, ada empat pilihan jawaban yang dikelompokkan dalam dua kategori, yaitu kategori rendah mencakup pilihan jawaban sangat tidak setuju dan tidak setuju; dan kategori tinggi mencakup pilihan jawaban setuju dan sangat setuju. Sementara untuk perilaku, opsi jawaban meliputi untuk kategori rendah mencakup pilihan jawaban tidak pernah dan jarang; sedangkan kategori tinggi mencakup jawaban selalu dan sering. Pengkategorian tersebut dibuat dalam jumlah genap dengan tujuan agar skala tersebut dapat 
ditransformasikan menjadi indikator satu-nol (dummy variable) secara tepat.

Uji persyaratan merupakan prasyarat untuk melakukan analisis regresi. Uji asumsi klasik dilakukan dengan menggunakan beberapa model pengujian, yaitu sebagai berikut :

\section{a. Pengujian linearitas}

Uji linieritas dilakukan untuk menentukan apakah variabel bebas $(\mathrm{X})$ dan variabel tak bebas (Y) berhubungan secara linier.

Untuk menghitungnya menggunakan program SPSS Versi 21 for windows. Uji linieritas regresi dilakukan dengan membandingkan nilai $F_{\text {hitung }}$ dengan $F_{\text {tabel }}$ atau membandingkan koefisien probabilitas (p) dengan taraf signifikansi $0,05(\alpha=0,05)$. Regresi berbentuk hubungan linier Jika $\mathrm{F}_{\text {hitung }}$ lebih besar dari $F_{\text {tabel }}$ atau nilai $\mathrm{p}$ (probabilitas) lebih kecil dari taraf signifikansi $(\alpha=0,05)$.

b. Pengujian Multikolinieritas

Sebelum analisis regresi linear berganda dilakukan maka terlebih dahulu diadakan uji multikolinieritas. Pengujian ini dimaksudkan untuk mengetahui apakah variabel independen yang terdapat dalam model regresi memiliki hubungan linier. Multikolinieritas artinya antar variabel independen yang terdapat dalam model regresi memiliki hubungan linier yang sempurna atau mendekati sempurna (koefisien korelasinya tinggi atau bahkan 1). Cara untuk mengetahui ada atau tidaknya gejala multikolinieritas antara lain dengan melihat nilai variance Inflation Factor (VIF) dan tolerance, apabila nilai VIF kurang dari 10 dan Tolerance lebih dari 0,1 maka dinyatakan tidak terjadi multikolinieritas, menurut Ghozali, 2001 (Priyatno, 2014:165). Untuk perhitungannya dilakukan dengan menggunakan program SPSS versi 21 for windows.
Pengujian hipotesis

Untuk menguji hipotesis penelitian ini, dilakukan dengan menggunakan analisis regrsi ganda yaitu menguji pengaruh supervisi akademik pengawas $\left(\mathrm{X}_{1}\right)$ dan kepemimpinan kepala sekolah $\left(\mathrm{X}_{2}\right)$ secara bersama-sama terhadap disiplin kerja guru (Y), Untuk menghitung koefisien regresi ganda digunakan program SPSS for windows versi 21.

a. Uji simultan

Dalam menganalisis pengaruh variabel dependen dengan semua independen tanpa ada satu variabel independen yang dikendalikan maka dapat diuji simultan. Interpretai terhadap koefisien regresi ganda untuk menyatakan bahwa kedua variabel memiliki kontribusi secara bersama-sama. Untuk uji simultan dapat menggunakan Uji-F

b. Uji parsial

Untuk menganalisis pengaruh antara variabel independen dan variabel dependen dengan salah satu variabel independennyua dikendalikan/tetap digunakan uji parsial.

\section{HASIL DAN PEMBAHASAN}

\section{Hasil}

Tujuan penelitian ini adalah untuk mengetahui pengaruh supervisi akademik pengawas dan kepemimpinan kepala sekolah terhadap kerja guru SMK negeri 1 Bantaeng. Hasil korelasi parsial dan analisis regresi ganda diperoleh probabilitas $(\mathrm{p}) 0,003<0,05$ sebagaimana yang ditunjukkan hasil SPSS for windows versi 21 , berikut:

\section{Model Summary}

\begin{tabular}{l|r|r|r|r}
\hline Model & $\mathrm{R}$ & R Square & $\begin{array}{l}\text { Adjusted R } \\
\text { Square }\end{array}$ & \multicolumn{2}{|l}{ Std. Error of the Estimate } \\
\hline 1 &, $408^{\mathrm{a}}$ &, 166 &, 140 & 7,272 \\
\hline
\end{tabular}

a. Predictors: (Constant), KKASEK, SPVWAS 
ANOVAa

\begin{tabular}{|c|c|c|c|c|c|c|}
\hline \multicolumn{2}{|c|}{ Model } & Sum of Squares & df & Mean Square & $\mathrm{F}$ & Sig. \\
\hline \multirow{3}{*}{1} & Regression & 675,499 & 2 & 337,749 & 6,386 &, $003^{b}$ \\
\hline & Residual & 3384,800 & 64 & 52,887 & & \\
\hline & Total & 4060,299 & 66 & & & \\
\hline
\end{tabular}

a. Dependent Variable: DSPGURU

b. Predictors: (Constant), KKASEK, SPVWAS

Coefficientsa

\begin{tabular}{r|r|r|r|r|r}
\hline Model & Unstandardized Coefficients & $\begin{array}{r}\text { Standardized } \\
\text { Coefficients }\end{array}$ & Sig. \\
\cline { 2 - 5 } & $\mathrm{B}$ & Std. Error & Beta & & \\
\hline (Constant) & 64,227 & 9,942 & &, 000 \\
SPVWAS &, 167 &, 122 &, 197 & 1,375 &, 174 \\
KKASEK &, 196 &, 109 &, 258 & 1,800 &, 077 \\
\hline
\end{tabular}

a. Dependent Variable: DSPGURU

Correlations

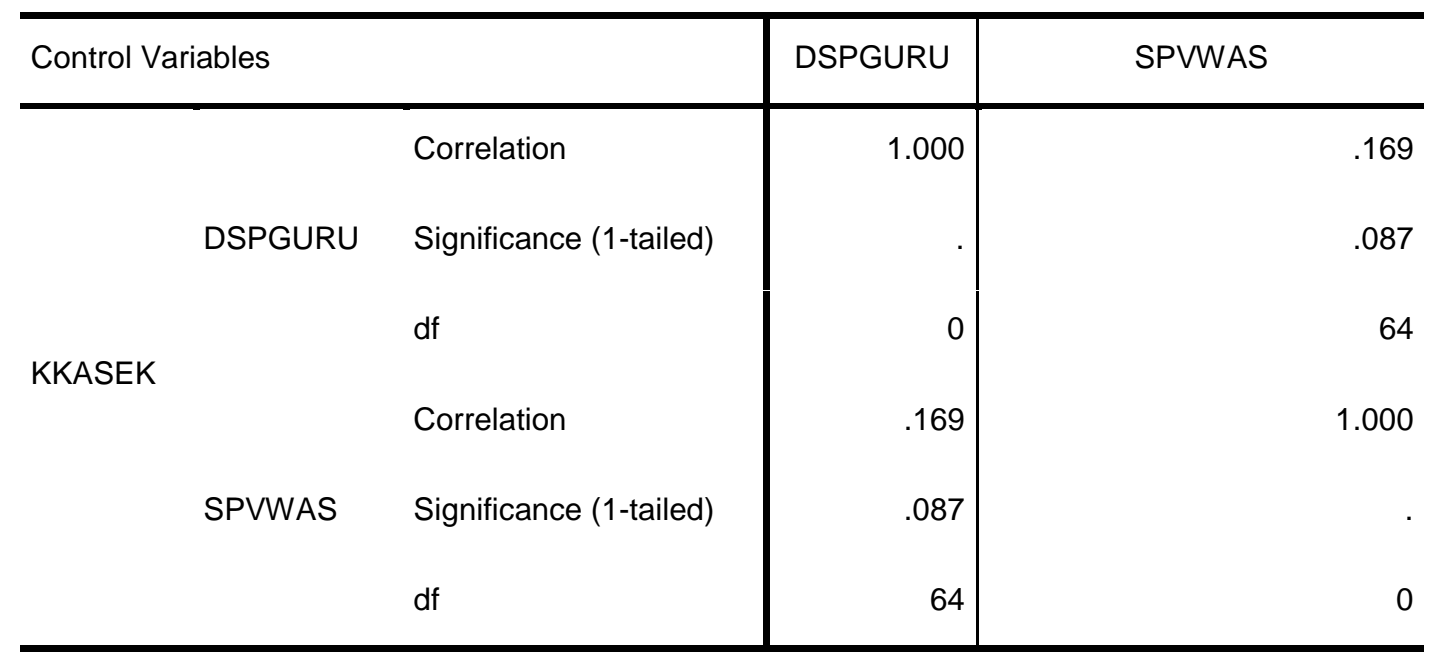

Correlations 


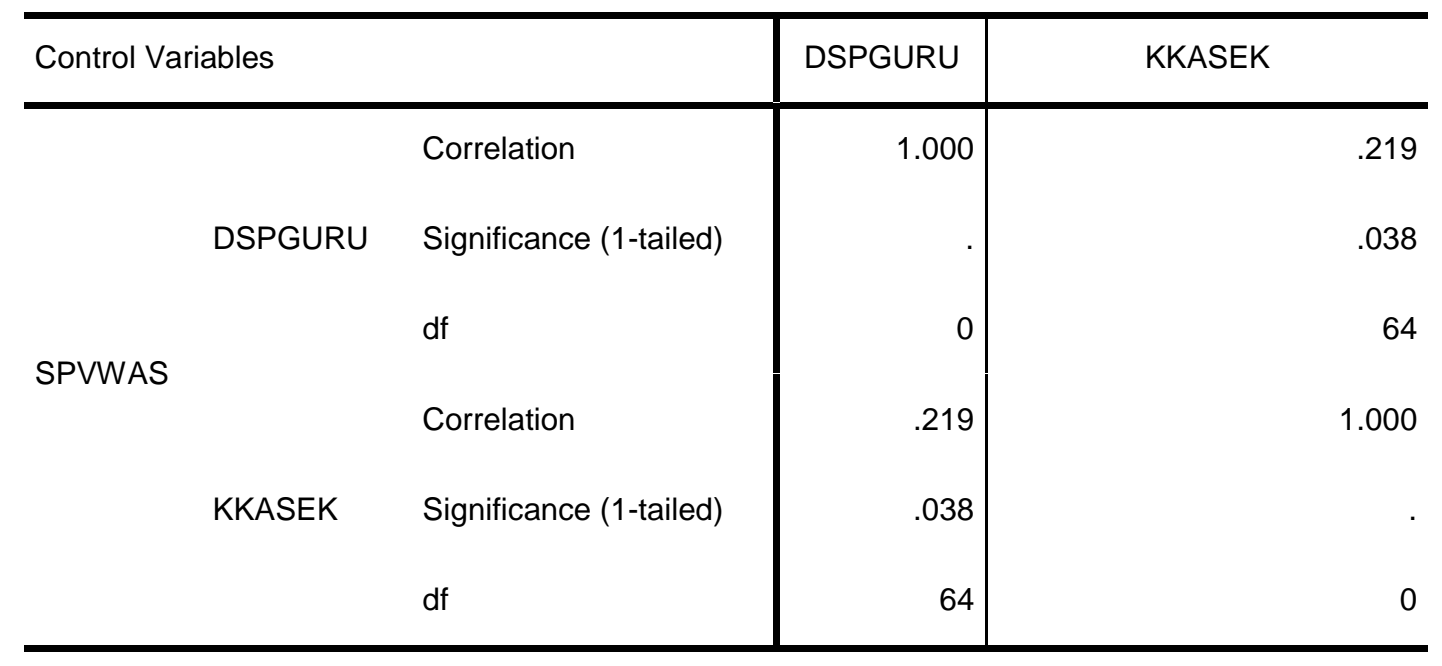

\section{Pembahasan}

Penelitian pendidikan mulai menunjukkan bahwa sangat penting bagi pengawas untuk membantu mengembangkan dan mendukung lingkungan belajar yang efektif untk memastikan keberhasilan setiap peseta didk, pengawas diharapkan untuk melayani dalam untuk melakukan fungsi utama untuk mempromosikan lingkungan belajar yang efektif.

Berdasarkan nilai $\mathrm{p}$ yang lebih kecil dari taraf signifikansi $(\alpha=0,05)$, maka regresi ganda dinyatakan memiliki keberartian (signifikan) sehingga dapat digunakan untuk memprediksi besarnya disiplin kerja guru yang dipengaruhi oleh variabel supervisi akademik pengawas dan kepemimpinan kepala sekolah secara bersamasama. Untuk mengetahui model regresi linier ganda digunakan hasil perhitungan pada Tabel Coefficientsa diperoleh $\beta_{0}=64,227, \beta_{1}=0,167$ dan $\beta_{2}=0,196$ sehingga model regresi linier $\mathrm{Y}=$ $64,227+0,167 \mathrm{X} 1+0,196 \mathrm{X} 2$, yang diinterpretasikan bahwa, Apabila supervisi akademik pengawas meningkat satu satuan maka akan meningkatkan disiplin kerja guru sebesar 0,167 dan peningkatan kepemimpinan kepala sekolah satu satuan maka akan meningkatkan disiplin kerja guru sebesar 0,196 pada konstanta 64,227. Dengan demikian disimpulkan bahwa supervisi akademik pengawas dan kepemimpinan sekolah secara bersama-sama berpengaruh tehadap disiplin kerja guru SMK Negeri 1 Bantaeng.
Berdasarkan hasil analisis Hasil uji regresi ganda data variabel supervisi akademik pengawas sekolah dengan variabel disiplin kerja guru dengan mengontrol kepemimponan kepala sekolah diperoleh nilai probabilitas $(\mathrm{p})=0,87$ > 0,05 dengan nilai koefisien supervisi akademik pengawas sekolah $\beta 1=0,167$, dinyatakan tidak memiliki keberartian. Berdasrkan hasil analisis supervise akademik pengawas terhadap disiplin kerja guru disimpulkan bahwa supevise akademik pengawas tidak berpengaruh terhadap disiplin kerja guru SMK negeri 1 Bantaeng.

Korelasi parsial dapat memasukkan satu variabel tambahan yang berfungsi sebagai pengontrol dari dua variabel yang berkorelasi terdahulu. Hasil output korelasi pada aplikasi SPSS for windows versi 21, sebagaimana ditunjukkan pada lampiran 9 halaman 151. Hasil pengujian menunjukkan bahwa koefisien korelasi antara variabel $\left(\mathrm{X}_{1}\right)$ dengan $(\mathrm{Y})$ yang dikontrol variabel $\left(\mathrm{X}_{2}\right)$ tidak berpengaruh dengan nilai- $p=0,087>\alpha=0,05$.

Hasil uji regresi ganda data variabel kepemimpinan kepala sekolah terhadap variabel disiplin kerja guru dengan mengontrol supervisi akademik diperoleh nilai probabilitas $(\mathrm{p})=$ $0,038<0,05$ dengan nilai koefisien kepemimpinan kepala sekolahsupervisi akademik pengawas sekolah $\beta_{2}=0,196$, dinyatakan memiliki keberartian. Berdasarkan hasil analisis kepemimpinan kepala sekolah terhadap disiplin kerja guru disimpulkan bahwa kepemimpinan kepala sekolah berpengaruh 
terhadap disiplin kerja guru SMK negeri 1 Bantaeng.

Korelasi parsial dapat memasukkan satu variabel tambahan yang berfungsi sebagai pengontrol dari dua variabel yang berkorelasi terdahulu. Hasil output korelasi pada aplikasi SPSS for windows versi 21, sebagaimana ditunjukkan pada lampiran 9 halaman 151. Hasil pengujian menunjukkan bahwa koefisien korelasi antara variabel $\left(\mathrm{X}_{2}\right)$ dengan $(\mathrm{Y})$ yang dikontrol variabel $\left(\mathrm{X}_{1}\right)$ berpengaruh dengan nilai- $p=0,038<\alpha=0,05$. Koefisien Deterninasi $\mathrm{D}=\mathrm{R}^{2}=(0,219)^{2}=0,047 \times 100 \%=$ $4,80 \%$. Hal ini mengandung pengertian bahwa $4,80 \%$ variabel disiplin kerja guru (Y) yang dapat dijelaskan oleh variabel kepemimpinan kepala sekolah dengan mengontrol variabel supervisi akademik pengawas. Hasil analisis deskriptif menunjukkan bahwa kepemimpinan kepala sekolah SMK Negeri 1 Bantaeng kecendengannya berada pada kategori tinggi. Hasil analisis regresi menunjukkan adanya arah hubungan yang positif antara kepemimpinan kepala sekolah dengan disiplin kerja guru dengan mengontrol supervisi akademik pengawas. Dengan demikian semakin tinggi kepemimpinan kepala sekolah maka semakin tinggi pula disiplin kerja guru, sebaliknya jika kepemimpinan kepala sekolah rendah maka disiplin kerja guru rendah.

Hal ini sesuai yang dikemukakan oleh Musbikin (2013: 47) bahwa, ketercapaian dan terwujudnya guru yang profesional sangat bergantung pada kecakapan/kemampuan kepemimpinan kepala sekolah. Menurut Karwati \& Priansa (2013 : 38) mengatakan bahwa, kepala sekolah merupakan salah satu komponen pendidikan yang berpengaruh dalam meningkatkan disiplin kerja guru. Selanjutnya lebih lanjut Karwati dan Priansa (2013: 136) menyatakan bahwa keberhasilan dan kesuksesan dalam mengelola organisasi sekolah dipengaruhi oleh kemampuan kepemimpinan kepala sekolah yang dimilikinya.

Pendapat ahli tersebut menunjukkan bahwa kepemimpinan yang dimiliki kepala sekolah sangat dibutuhkan karena berperan dalam mengembangkan sekolah serta meningkatkan disiplin kinerja dan profesionalisme guru.

\section{SIMPULAN DAN SARAN}

Berdasarkan temuan penelitian dan pemabahasannya yang telah diuraikan diatas maka dapat disimpulkan sebagai berikut Supervisi akademik pengawas dan kepemimpinan kepala sekolah secara bersamasama berpengaruh terhadap disiplin kerja guru SMK Negeri 1 Bantaeng. Supervisi akademik pengawas tidak berpengaruh terhadap disiplin kerja guru SMK Negeri 1 Bantaeng dengan mengontrol kepemi-mpinan kepala sekolah. Kepemimpinan kepala sekolah berpengaruh terhadap disiplin kerja guru SMK Negeri 1 Bantaeng dengan mengontrol supervisi akademik pengawas.

Selanjutnya disarankan hal-hal berikut:: Pemerintah dan Kepala Dinas Pendidikan: (1) Mengadakan pelatihan dan sejenisnya kepada pengawas sekolah untuk meningkatkan kompetensi pengawas sekolah khususnya kompetensi supervisi akademik pengawas sekolah.(2) Hendaknya merekrut pen-gawas sekolah berdasarkan kompetensi dan kualifikasi sebagaimana yang dipersyaratkan dalam Peraturan Menteri Pendidikan Nasional Nomor 12 Tahun 2007 tentang standar pengawas sekolah/madrasah. Kepala Sekolah : Hendaknya tetap meningkatkan kemampuan kepemimpinannya supaya dapat membina disiplin kerja guru kearah yang lebih baik. Pengawas Sekolah; (1) Hendaknya berupaya meningkatkan kompetensi khususnya kompetensi supervisi akademik pengawas sekolah sebagaimana yang disyaratkan pada pengawas sekolah. (2) Meningkatkan frekuensi kunjungan di sekolah binaan. (3) Melakukan bimbingan serta memberikan bantuan profesional kepada guru. Guru (1)Hendaknya selalu meningkatkan disiplin kerja dalam melaksanakan tugas baik tugas pokok maupun tugas tambahan. (2) Mintalah bantuan/bimbingan pengawas sekolah dan kepala sekolah yang terkait dengan masalah pelaksanaan tugas pokok maupun tugas tambahan seperti bagaimana membuat rencana pembelajaran, pelaksanaan pembelajaran dan evaluasi hasil pembelajaran dan lainya. Merekomendasikan kepada peneliti selanjutnya, untuk mencari variabel-variabel lain yang mempengaruhi disiplin kerja guru, selain variabel supervisi akademik dan kepemimpinan kepala sekolah, mengingat kedua variabel 
tersebut hanya berkontribusi sebesar $17 \%$ terhadap disiplin kerja guru.

\section{DAFTAR RUJUKAN}

Hadi, Sutrisno. 1991. Analisis Butir untuk Instrumen Angket, Tes, dan Skala Nilai dengan Basica. Yogyakarta: Andi Offset.

Kartono, Kartini. 2013. Pemimpin dan Kepemimpinan. Jakarta: PT Raja grafindo Persada .

Karwati Euis, \& Priansa Donni Juni. 2013. Kinerja dan Profesionalisme Kepala Sekolah Membangun Sekolah yang Bermutu. Bandung: Alfabeta

Mardapi, Djemari. 2012. Pengukuran Penilaian dan Evaluasi Pendidikan. Yogyakarta: Nuha Medika.

Masaong, Abd. Kadim. 2012. Supervisi Pembelajaran dan Pengembangan Kapasitas Guru: Memberdayakan Pengawas sebagai Gurunya Guru. Bandung Alfabeta.

Musbikin, \& Imam. 2013. Menjadi Kepala Sekolah yang Hebat. Pekanbaru Riau: Zanafa Publishing.

Noor, Juliansyah. 2013. Metodologi Penelitian. Jakarta: Kencana Prenada Media Group.

Permendiknas No. 12 Tahun 2007 Tentang Standar Pengawas Sekolah. Jakarta: Depdiknas.

Priyatno, Duwi. 2014. SPSS 22 Pengolah Data Terpraktis. Yogyakarta: Andi Offset.

Ratminto,\& Winarsih Atik Septi. 2005. Manajemen Pelayanan; Pengembangan Model Konseptual. Penerapan Citizens dan Standar Pelayanan Minimal. Yogyakarta: Pustaka Pelajar.

Sagala, Syaiful 2010. Supervisi Pembelajaran. Bandung: Alfabeta . 